Article

\title{
The Effect of Polymers on Drug Release Kinetics in Nanoemulsion In Situ Gel Formulation
}

\author{
K. Reeta Vijaya Rani ${ }^{1}$, Sruthi Rajan ${ }^{2}$ D, Mullaicharam Bhupathyraaj ${ }^{3, *}$, R. Krishna Priya ${ }^{4}$, Nirmala Halligudi ${ }^{3}$, \\ Mohammad Abobakr Al-Ghazali ${ }^{3}$ (D), Sathvik B. Sridhar ${ }^{5}$, Javedh Shareef ${ }^{5}$, , Sabin Thomas ${ }^{6}$, \\ Saleem M. Desai ${ }^{7}$ and Pandurang D. Pol ${ }^{8}$
}

Citation: Vijaya Rani, K.R.; Rajan, S.; Bhupathyraaj, M.; Priya, R.K.;

Halligudi, N.; Al-Ghazali, M.A.;

Sridhar, S.B.; Shareef, J.; Thomas, S.; Desai, S.M.; et al. The Effect of

Polymers on Drug Release Kinetics in

Nanoemulsion In Situ Gel

Formulation. Polymers 2022, 14, 427.

https://doi.org/10.3390/

polym 14030427

Academic Editor:

Andreea-Teodora Iacob

Received: 6 December 2021

Accepted: 10 January 2022

Published: 21 January 2022

Publisher's Note: MDPI stays neutral with regard to jurisdictional claims in published maps and institutional affiliations.

Copyright: (C) 2022 by the authors. Licensee MDPI, Basel, Switzerland. This article is an open access article distributed under the terms and conditions of the Creative Commons Attribution (CC BY) license (https:// creativecommons.org/licenses/by/ $4.0 /)$.
1 Surya School of Pharmacy, Vikravandi, Villupuram 605652, Tamilnadu, India; reeta_rani07@yahoo.co.in

2 Periyar College of Pharmaceutical Sciences, Tiruchirappalli 620021, Tamilnadu, India; sruthirajan1997@gmail.com

3 College of Pharmacy, National University of Science and Technology, Muscat 130, Oman; nirmalahalligudi@nu.edu.om (N.H.); mohammadalghazali@nu.edu.om (M.A.A.-G.)

4 College of Engineering, National University of Science and Technology, Muscat 130, Oman; krishnapriya@nu.edu.om

5 RAK College of Pharmaceutical Sciences, RAK Medical and Health Sciences University, Ras Al Khaimah 11172, United Arab Emirates; sathvik@rakmhsu.ac.ae (S.B.S.); javedh@rakmhsu.ac.ae (J.S.)

6 School of Pharmacy, College of Pharmacy \& Nursing, University of Nizwa, Nizwa 616, Oman; sabin@unizwa.edu.om

7 Anjuman Arts, Science, Commerce College of PG Studies in English, Vijayapura 586101, Karnataka, India; saleem_m_desai@yahoo.co.in

8 Department of Chemistry, BHS Arts and TGP Science College, Jamkhandi 586103, Karnataka, India; polpandurang@yahoo.in

* Correspondence: mullaicharam@nu.edu.om

Abstract: Glaucoma is an ocular condition characterized by elevated intraocular pressure (IOP). Conventional treatments of glaucoma face poor corneal permeability and bioavailability. To address these issues, a nanoemulsion in situ gel of Timolol maleate was developed in this study by adding the polymer Carbopol 934p. Using Carbopol 934p, a novel ophthalmic $\mathrm{pH}$-induced nanoemulsion in situ gel was formulated. The formulation was liquid at $\mathrm{pH} 4$ and quickly gelled when the $\mathrm{pH}$ was raised to 7.4 (Lacrimal $\mathrm{pH})$. The $\mathrm{pH}$-triggered in situ gelling mechanism demonstrated continuous drug release over a $24 \mathrm{~h}$ cycle. A total of nine trial formulations were prepared $\left(\mathrm{NEI}_{1}-\right.$ $\mathrm{NEI}_{9}$ ) and subjected to various physicochemical and in vitro evaluations. According to the in vitro release kinetics, the drug release of Timolol maleate nanoemulsion in situ gel $\mathrm{NEI}_{5}$ followed zeroorder kinetics, with a release exponent value of 0.902 , indicating that the mechanism of release was non-Fickian diffusion regulated. In vivo results showed that Timolol maleate nanoemulsion in situ gel $\mathrm{NEI}_{5}$ provided a better-sustained release of the drug, compared with the Timolet OD eye drops. The formulation is stable in storage, with no distinguishable change in appearance, physical properties, quality, and percentage drug release. $\mathrm{NEI}_{5}$ also reduces drug administration frequency, which improves patient compliance. Timolol maleate nanoemulsion in situ gel $\mathrm{NEI}_{5}$ achieved the goal of controlled drug delivery with extended-release and cost-effectiveness, lowering the dosage and frequency of drug administration, and thus may improve patient compliance. In conclusion, the stable nanoemulsion in situ gel of Timolol maleate $\mathrm{NEI}_{5}$ decreases intraocular pressure (IOP) over a prolonged period.

Keywords: Carbopol 934p; glaucoma; Timolol maleate; nanoemulsion; in situ gel

\section{Introduction}

Nanoemulsions are a group of dispersed particles used for pharmaceutical and biomedical aids and vehicles that show great promise for the future of drug therapies, cosmetics, 
diagnostics, and biotechnologies. Nanoemulsions are defined as oil-in-water $(\mathrm{o} / \mathrm{w})$ emulsions, with mean droplet diameters ranging from 50 to $1000 \mathrm{~nm}$ [1]. According to the second law of thermodynamics, the $\mathrm{o} / \mathrm{w}$ nano-sized emulsion is subjected to various instability processes such as aggregation, flocculation, coalescence, Ostwald ripening, and hence eventual phase separation [2]. Unlike thermodynamically stable microemulsions and clear transparent liquid systems, macro (coarse)- and nano-sized emulsions are meta-stable dispersions. However, the stability of the o/w macro (coarse)- and nano-sized emulsions can substantially be improved with the help of suitable emulsifiers or emulators that are capable of forming a mono- or multilayer coating film around the dispersed oil droplets to reduce interfacial tension and to increase droplet-droplet repulsion [3].

The proper ratio of oil:water: gum, the appropriate concentration of emulsifying agents, and high-efficiency emulsification equipment that are used to make very low droplet size are the most important factors to develop the $\mathrm{o} / \mathrm{w}$ nano-sized emulsion with improved stability over the desired period (in comparison with coarse emulsion) can be obtained. The advantages of the nano-sized emulsion system include natural biodegradability, sub-micrometer droplet size range, stabilizability, and substantial drug solubilization either at the innermost oil phase or the $\mathrm{o} / \mathrm{w}$ interface, minimizing side effects, and improved bioavailability. Due to these advantages, the nano-sized emulsion is now recognized as a promising drug delivery vehicle or carrier for parenteral and topical (ocular and percutaneous) applications [4-6].

Initially, in situ gel drug delivery systems are in sol form. There is no gelation process occur. Once administered inside the body through any one of the many routes, such as oral, ocular, rectal, vaginal, injectable, and intraperitoneal routes, the sol form will be converted to gel form due to the gelation process. In ophthalmic products, the formation of viscoelastic gel occurs after the installation of the liquid form of in situ forming hydrogels. These hydrogels are administered through the ocular cul-de-sac route where the hydrogel goes through a phase transition [7].

Natural polymers are mostly used in the preparation of in situ gel dosage form. For example, xyloglucan, a water-soluble anionic polysaccharide of gellan gum and algin are used for ocular drug delivery system.

Many components such as ocular drugs are used to alter the function of the nervous system. Non-steroidal anti-inflammatory drugs are used to prevent growth or to kill microorganisms. The disadvantages of using conventional ocular drug delivery systems such as eye drops are poor bioavailability and poor therapeutic response.

The reason behind these disadvantages is the fast removal of the drug from the eyes due to elevated tear fluids turnover. To overcome these disadvantages, in situ gels are prepared as the ophthalmic dosage form. Sustained drug release is possible from these in situ gels. In situ gels are viscous gels and have longer pre-corneal contact times, compared with conventional eye drops.

The gellan gum undergoes changeover into the gel state due to the temperature and ionic condition $\left(\mathrm{Ca}^{++}\right)$in the tear fluid. Due to this property, an aqueous solution of gellan is used in ophthalmic drug delivery.

Glaucoma is a slowly progressive pathology that can result in the loss of peripheral vision, decreased contrast sensitivity, and loss of visual acuity. Due to the asymptomatic nature of the early phases of the disease, most patients experience undiagnosed loss of vision until the advanced stages of the disease have occurred. Thus, the disease is known as the "silent thief of sight". This indolent optic neuropathy is characterized structurally by a loss of retinal ganglion cells and optic nerve axons. Glaucoma is the second leading cause of the world's blindness, with nearly 70 million cases worldwide and accounting for $12 \%$ of all cases of preventable blindness [8-10]. It is estimated that by 2020, close to 4 million Americans will have glaucoma, with $50 \%$ undiagnosed and approximately 120,000 individuals developing blindness [11,12].

This work aims to extend drug availability in glaucomatous conditions by adding a different proportion of the polymer Carbopol 934p. Carbopol is a polyacrylic acid polymer, 
which shows a sol-to-gel transition in an aqueous solution as the $\mathrm{pH}$ is raised above its $\mathrm{PK}_{\mathrm{a}}$ of about 5.5, and it is widely used in ophthalmology to enhance precorneal retention to the eye [13]. Moreover, Carbopol exhibits excellent mucoadhesive properties when compared with other polymers.

Carbopol 934p is also used in liquid or semisolid pharmaceutical formulations as rheology modifiers. Due to this property of Carbopol 934p, the immediate release kinetics has been modified as zero-order kinetics of the formulation, which provides the more beneficial effect of the gel formulation [14,15].

\section{Materials and Methods}

\subsection{Materials}

A gift sample of Timolol maleate (Pure drug, Madras Pharma (P) Ltd., Chennai, India. Castor oil (Lab grade), Tween 80 (Lab grade), benzalkonium chloride, and glycerol (Lab grade) were purchased from Nice Chemicals (P) Ltd., Chennai, India. Potassium dihydro orthophosphate (Lab grade) was purchased from Scientific Chemicals, Chennai, India. Sodium hydroxide (Lab grade) was purchased from Hi Pure Fine Chem Industries, Chennai, India.

\subsection{Methodology}

\subsubsection{Formulation of In Situ Gelling System}

A conventional emulsion was prepared by dissolving Timolol maleate in castor oil, and glycerol was used as a cosolvent with continuous stirring in a magnetic stirrer. The aqueous solution of Tween 80 and a sufficient amount of water was added and stirred well. The oil phase was added dropwise in continuous phase with stirring at ambient temperature and added the benzalkonium chloride as a preservative. This conventional emulsion was converted into nanoemulsions with the help of a sonication mechanism. The final step was the addition of Carbopol 943p at pH 4. A total number of nine trial batches were prepared for the optimization of process variables [16-18]. The process flowchart for nanoemulsion in situ gel is shown in Figure 1.

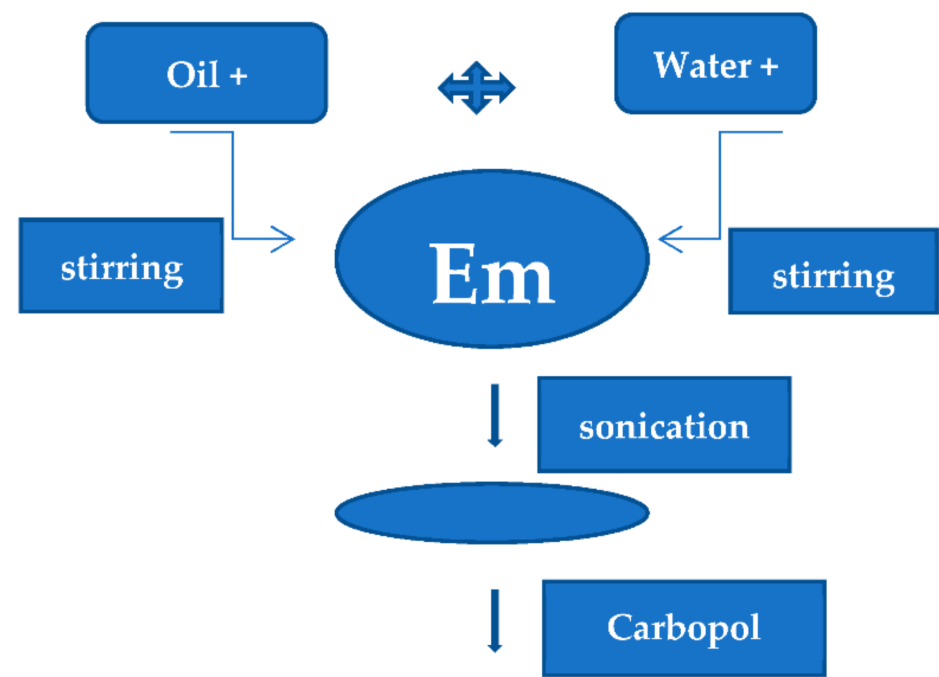

\section{Nanoemulsi}

Figure 1. Preparation of nanoemulsion in situ gel by the ultra-sonication method.

Different concentrations of emulsifying agents and gelling agents were used in trial batches and studied to have a sustaining effect for $24 \mathrm{~h}$. In all batches, the concentration of drug and oil were kept constant; the data are presented in Table 1. 
Table 1. Compositions of the trial batch.

\begin{tabular}{|c|c|c|c|c|c|c|c|c|c|}
\hline Ingredients & $\mathrm{NEI}_{1}$ & $\mathrm{NEI}_{2}$ & $\mathrm{NEI}_{3}$ & $\mathrm{NEI}_{4}$ & $\mathrm{NEI}_{5}$ & $\mathrm{NEI}_{6}$ & $\mathrm{NEI}_{7}$ & $\mathrm{NEI}_{8}$ & $\mathrm{NEI}_{9}$ \\
\hline Timolol maleate (mg) & 100 & 100 & 100 & 100 & 100 & 100 & 100 & 100 & 100 \\
\hline Castor oil (mL) & 5 & 5 & 5 & 5 & 5 & 5 & 5 & 5 & 5 \\
\hline Tween 80 (mL) & 3 & 3 & 3 & 3.5 & 3.5 & 3.5 & 4 & 4 & 4 \\
\hline Glycerol (mL) & 2 & 2 & 2 & 2 & 2 & 2 & 2 & 2 & 2 \\
\hline Carbopol 934p & 300 & 600 & 900 & 300 & 600 & 900 & 300 & 600 & 900 \\
\hline $\begin{array}{l}\text { Benzalkonium } \\
\text { chloride (\%) }\end{array}$ & 0.02 & 0.02 & 0.02 & 0.02 & 0.02 & 0.02 & 0.02 & 0.02 & 0.02 \\
\hline Distilled water $(\mathrm{mL})$ & q.s & q.s & q.s & q.s & q.s & q.s & q.s & q.s & q.s \\
\hline
\end{tabular}

\subsubsection{Characterization}

The following parameters were evaluated for all the formulations to confirm the desired release of drug and stability of formulation: visual appearance and clarity, $\mathrm{pH}$, viscosity, gelling capacity, and particle size analysis [19-23].

Visual Inspection

A visual inspection was carried out behind the dark background to observe the clarity and proper appearance of each formulation.

$\mathrm{pH}$

The $\mathrm{pH}$ of each formulation was measured by using a digital $\mathrm{pH}$ meter (Elico).

Viscosity

A Brookfield viscometer (Brookfield DV-II + Pro viscometer (The Bharat Instruments \& Chemicals, Ludhiana, India) with a small sample adapter, having spindle number SC4$18 / 13 R$, was used to quantify the viscosity of the prepared nanoemulsions. The gelling property was determined by mixing the 25:7 ratio of the formulation with simulated tear fluid, and the gelation was evaluated by visual examination. The time taken for the formation of gel and the time taken for dissolution was recorded.

\section{Particle Size}

Particle size distribution and the average size of particles present in the formula were determined by blue wave analytical mode by DLS method using Zetasize. Figure 2. Atomic force microscopy [24] was used to confirm the size and shape of the particles (Figure 3).

\section{Sterilization and Sterility Testing}

Moist heat sterilization is used for killing microorganisms. Autoclaving, as an efficient method to inactivate bacteria, viruses, and other biological material, is recommended for the disposal of regulated medical waste.

In this study, Timolol maleate nanoemulsion in situ gel was sterilized by moist heat sterilization. This process was carried out at $121^{\circ} \mathrm{C}$ for $15 \mathrm{~min}$ under pressures of $15 \mathrm{lb} / \mathrm{sq}$. inch. In this process, the moist-heat vapors at high temperatures precipitate or coagulate the cell wall proteins and destroy the microorganisms. The test for sterility is intended for detecting the presence of viable forms of bacteria, fungi, and yeast in sterilized preparations [25-28].

\section{Content Uniformity}

The vials $(n=3)$ containing the preparation were shaken for $2-3 \mathrm{~min}$, and $100.0 \mu \mathrm{L}$ of the preparations were transferred aseptically to sterile $25.0 \mathrm{~mL}$ volumetric flasks with a micropipette, and the final volume was made with phosphate buffer $\mathrm{pH}$ 7.4. The solution 
was filtered through a $0.45 \mu \mathrm{m}$ membrane, and the concentration of Timolol maleate was determined at $295 \mathrm{~nm}$, using a double beam UV spectrophotometer [29-33].

\section{Compatibility}

Drug-excipient compatibility studies were carried out by using Fourier transform infrared (FTIR) spectral analysis. The FTIR absorption spectra of the pure drug and physical admixtures of the drug with various excipients were taken in the range of $400-4000 \mathrm{~cm}^{-1}$ using the $\mathrm{KBr}$ disc method (Shimadzu IR-Prestige-21) and observed for characteristic peaks of the drug. The FTIR absorption spectra optimized formula is given in Figure 4.

\section{In Vitro Release Study}

The in vitro dissolution of the prepared in situ gel formulations was performed by diffusion method using an open embedded glass tube. A cellophane membrane presoaked in the dissolution media was fixed in the open end of the glass tube, considered as donor compartment that fixed inside $100 \mathrm{~mL}$ beaker containing $50 \mathrm{~mL}$ of phosphate buffer $\mathrm{pH}$ 7.4, which was used as receptor compartment. Then, $1 \mathrm{ml}$ of the preparation was allowed to diffuse via the cellophane membrane to the receptor compartment, which was kept on a magnetic stirrer at $37^{\circ} \mathrm{C}$. Afterward, $5 \mathrm{~mL}$ sample was withdrawn in a specified time interval up to $24 \mathrm{~h}$ and analyzed by using Shimadzu Double beam UV-Visible spectrophotometer at $295 \mathrm{~nm}$ [34]. The cumulative \% drug release in all the formulations were given in Table 5 and Figure 5.

\section{In Vivo Studies}

The intraocular pressure measurement in albino rabbits was studied in Periyar College of Pharmaceutical Sciences, Tiruchirappalli, Tamilnadu, India. (265/1/101/CPCSEA).

\section{Intraocular Pressure Studies}

The intraocular pressure study was conducted in albino rabbits (Haffkin strain) of either sex weighing between $1.8 \mathrm{~kg}$ and $2.5 \mathrm{~kg}$. All experiments were carried out at room temperature [35].

Six rabbits were used for this study. Reduction in intraocular pressure (IOP) was measured by Schiotz tonometer. Minimum two readings of IOP were taken before administration of nanoemulsion in situ gel, which was denoted as $\mathrm{I}_{\mathrm{o}}$. The formulation $(0.05 \mathrm{~mL})$ was administered with the help of an insulin syringe in the lower cul-de-sac of one eye.

The control $(0.05 \mathrm{~mL})$ was administered in the right eye. Reduction in IOP at time $t$ was denoted as $I_{t}$, and observations were recorded. The graph is plotted as $I_{n}$ versus time where $I_{n}=I_{t}-I_{o} / I_{t}$. The same animal was used repeatedly, allowing a minimum of two days between two successive experiments. The results were compared with commercially available Timolet eye drops (containing $0.5 \% w / v$ of Timolol maleate manufactured by Sun Pharmaceuticals, Chennai, India).

Accelerated Stability

Accelerated Stability studies were carried out by exposing $\mathrm{NEI}_{5}$ at various temperatures of $40{ }^{\circ} \mathrm{C}$, and $2-8{ }^{\circ} \mathrm{C}$. After a specific period of storage for stability, the in situ gel was evaluated for physical parameters, in vitro drug release, and drug content [36-39].

\section{Results}

The prepared in situ gel formulations were evaluated for various physicochemical evaluations such as visual appearance, clarity, gelling capacity, viscosity in $\mathrm{pH} 4$ and $\mathrm{pH}$ 7.4, particle size, drug content, compatibility, and in vitro diffusion studies. Based on the Physicochemical and in vitro diffusion studies, formulation NEI5 has been selected and subjected to sterilization, in vivo, sterility testing, and accelerated stability studies. There was no microbial growth found for not less than 14 days at $30^{\circ}$ to $35^{\circ} \mathrm{C}$ in a fluid thioglycollate medium. The intraocular pressure effect of the Timolol maleate nanoemulsion 
in situ gel was compared with the effect of aqueous Timolet eye drops with $0.5 \% w / v$. At $40{ }^{\circ} \mathrm{C}$, there was a slight decrease in the consistency after three months. There was an increase in the viscosity after gelling. Additionally, the gel formed in situ maintained its integrity without dissolving or eroding for a prolonged period. Results are represented in Tables 2-8 and Figures 1 and 2.

\subsection{Visual Appearance, Clarity, and Gelling Capacity}

Evaluation of Visual appearance, Clarity, and Gelling Capacity carried out to find out the physicochemical properties of nine formulations having different compositions.

The status of all the nine formulations in terms of Visual appearance, Clarity, and Gelling Capacity is shown in Table 2.

Table 2. Visual appearance, Clarity, and Gelling Capacity.

\begin{tabular}{|c|c|c|c|c|c|c|c|c|c|}
\hline Evaluation & $\mathrm{NEI}_{1}$ & $\mathrm{NEI}_{2}$ & $\mathrm{NEI}_{3}$ & $\mathrm{NEI}_{4}$ & $\mathrm{NEI}_{5}$ & $\mathrm{NEI}_{6}$ & $\mathrm{NEI}_{7}$ & $\mathrm{NEI}_{8}$ & $\mathrm{NEI}_{9}$ \\
\hline Visual appearance & $\mathrm{T}$ & $\mathrm{T}$ & $\mathrm{T}$ & $\mathrm{T}$ & $\mathrm{T}$ & $\mathrm{T}$ & $\mathrm{T}$ & $\mathrm{T}$ & $\mathrm{T}$ \\
\hline Clarity & $\mathrm{C}$ & $\mathrm{C}$ & $\mathrm{C}$ & $\mathrm{C}$ & $\mathrm{C}$ & $\mathrm{C}$ & $\mathrm{C}$ & $\mathrm{C}$ & $\mathrm{C}$ \\
\hline Gelling capacity & + & ++ & +++ & + & ++ & +++ & + & ++ & +++ \\
\hline
\end{tabular}

T-transparent, C-Clear, + gels slowly and dissolves; ++ gelation immediate and remains for a few hours; +++ gelation immediate and remains for an extended period.

\subsection{Evaluation of Viscosity}

In order to know the rheological property of the nine formulations in two different $\mathrm{pH} 4$ and, $\mathrm{pH} 7.4$ the viscosity was measured by using A Brookfield viscometer. The values of viscosity are given in Table 3.

Table 3. Evaluation of viscosity in $\mathrm{pH} 4$ and $\mathrm{pH} 7.4$.

\begin{tabular}{|c|c|c|c|c|c|c|c|c|c|c|}
\hline \multirow{2}{*}{\multicolumn{2}{|c|}{ Evaluation }} & \multicolumn{9}{|c|}{ Viscosity (cps) } \\
\hline & & $\mathrm{NEI}_{1}$ & $\mathrm{NEI}_{2}$ & $\mathrm{NEI}_{3}$ & $\mathrm{NEI}_{4}$ & $\mathrm{NEI}_{5}$ & $\mathrm{NEI}_{6}$ & $\mathrm{NEI}_{7}$ & $\mathrm{NEI}_{8}$ & $\mathrm{NEI}_{9}$ \\
\hline \multirow{2}{*}{$\mathrm{pH}$} & 4 & 102 & 120 & 140 & 115 & 129 & 143 & 113 & 126 & 140 \\
\hline & 7.4 & 226 & 260 & 290 & 230 & 265 & 299 & 230 & 260 & 302 \\
\hline
\end{tabular}

\subsection{Particle Size Analysis}

Particle size distribution and the average size of particles was generated by using the formula were determined by blue wave analytical mode by DLS method using Zeta size. As shown in Figure 2, the report showed that the average mean diameter range was $76 \mathrm{~nm}$ to $1000 \mathrm{~nm}$.

\subsection{Atomic Force Microscopy}

In order to confirm the size and shape of the particles, Atomic force microscopy was used. to confirm the size and shape of the particles (Figure 3). The surface morphology analyzed by atomic force microscopy (AFM) result showed a uniform, spherical, and discrete particle without aggregation, which was smooth in the surface and the nanosize range, at $260.4-351.8 \mathrm{~nm}$.

\subsection{Drug Content}

The concentration of Timolol maleate of nine formulations was determined at $295 \mathrm{~nm}$, using a double beam UV spectrophotometer. The percent-age of drug content in all the formulations given in Table 4 . 


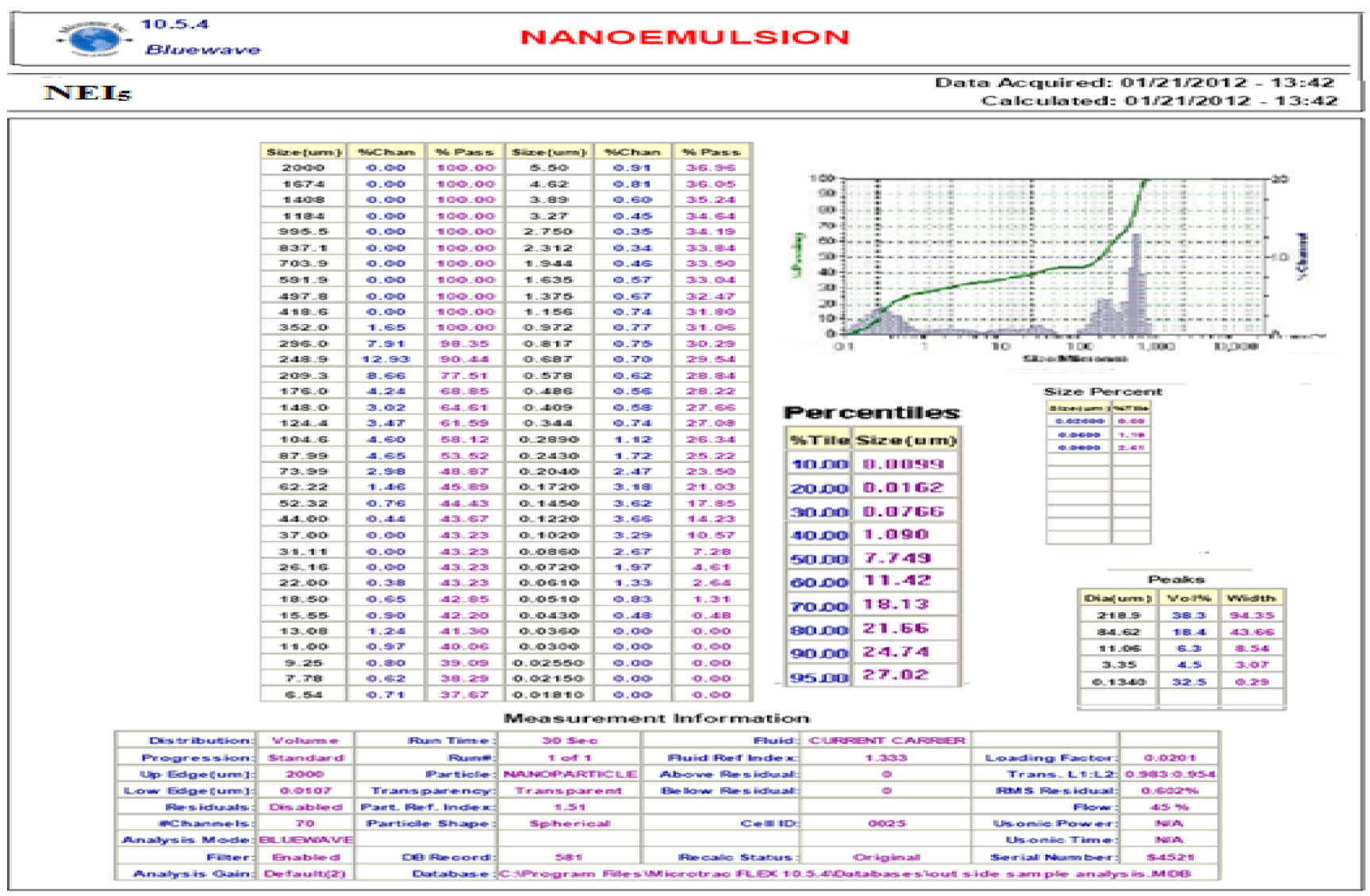

Figure 2. Particle size analysis.

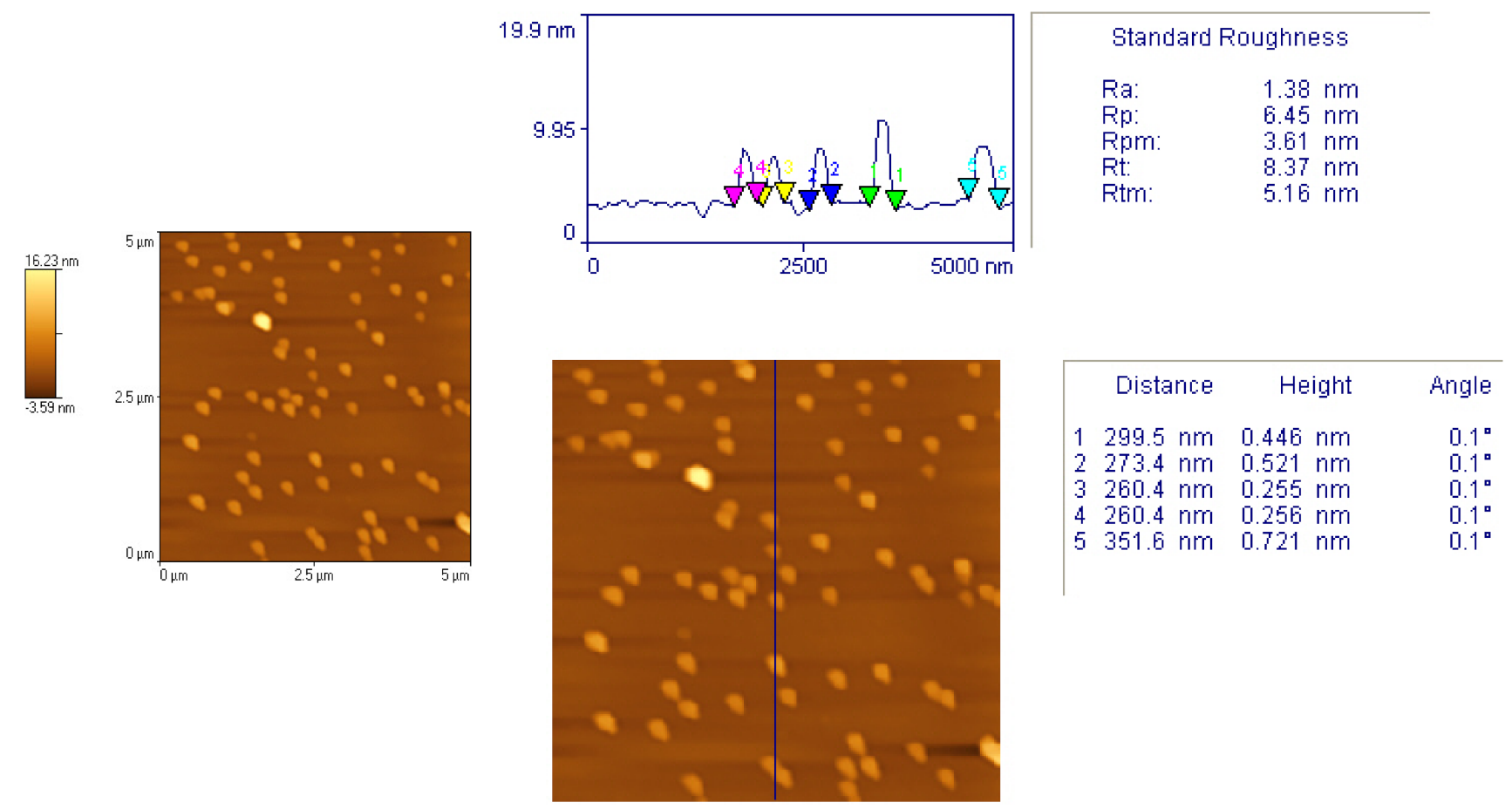

Figure 3. Atomic force microscopy. 
Table 4. Drug content.

\begin{tabular}{cccccccccc}
\hline Formulation & $\mathbf{N E I}_{\mathbf{1}}$ & $\mathbf{N E I}_{\mathbf{2}}$ & $\mathbf{N E I}_{\mathbf{3}}$ & $\mathbf{N E I}_{\mathbf{4}}$ & $\mathbf{N E I}_{\mathbf{5}}$ & $\mathbf{N E I}_{\mathbf{6}}$ & $\mathbf{N E I}_{\mathbf{7}}$ & $\mathbf{N E I}_{\mathbf{8}}$ & $\mathbf{N E I}_{\mathbf{9}}$ \\
\hline Drug Content (\%) & 101.6 & 99.56 & 98.32 & 100.36 & 99.79 & 98.25 & 100.98 & 99.43 & 98.29 \\
\hline
\end{tabular}

\subsection{Compatibility Studies}

The FTIR absorption spectra optimized formula is given in Figure 4. The FTIR spectra of formulation NEI5 showed that there were no extra peaks other than the normal peak in the spectra of the mixture of the extracts, containing active constituents, and excipients.

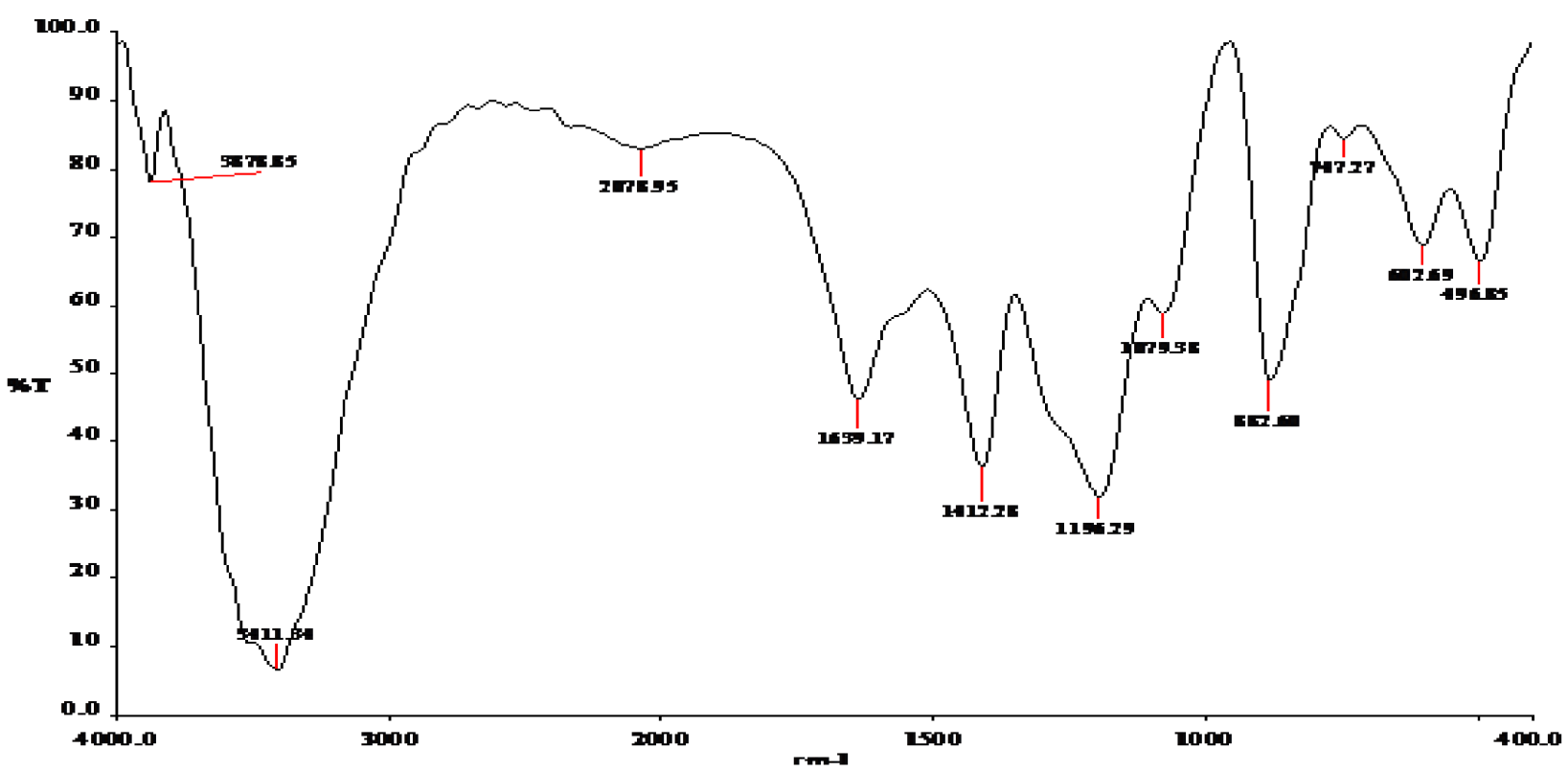

Figure 4. FTIR spectra of NEI5.

\subsection{In Vitro Diffusion Drug Release Profile}

The in vitro dissolution of the prepared in situ gel formulations was performed by diffusion method to find out the release profile of nine formulations. The cumulative $\%$ drug release in all the formulations were given in Table 5 and Figure 5.

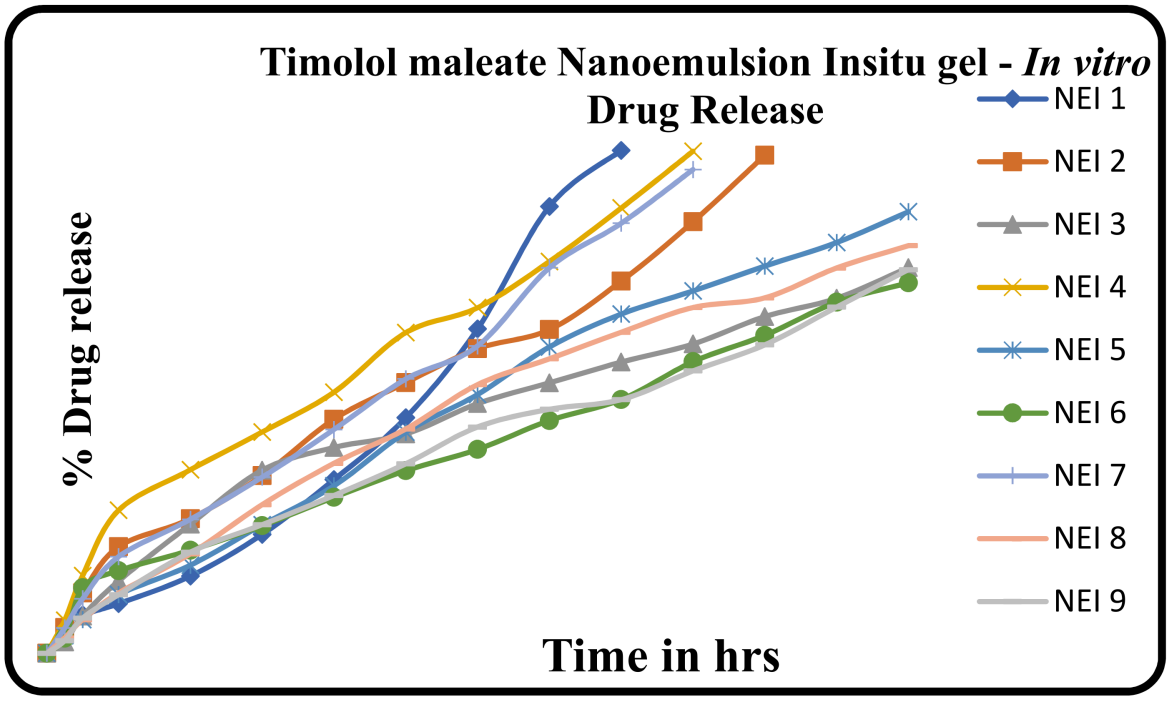

Figure 5. Trail batch. Comparative in vitro diffusion profile of trial formulations. 
Table 5. Diffusion profiles of formulations trial batch: $\mathrm{NEI}_{1}-\mathrm{NEI}_{9}$.

\begin{tabular}{|c|c|c|c|c|c|c|c|c|c|}
\hline \multirow{2}{*}{$\begin{array}{l}\text { Time } \\
\text { (min) }\end{array}$} & \multicolumn{9}{|c|}{ Cumulative \% Drug Release \pm S.D. * } \\
\hline & $\mathrm{NEI}_{1}$ & $\mathrm{NEI}_{2}$ & $\mathrm{NEI}_{3}$ & $\mathrm{NEI}_{4}$ & $\mathrm{NEI}_{5}$ & $\mathrm{NEI}_{6}$ & $\mathrm{NEI}_{7}$ & $\mathrm{NEI}_{8}$ & $\mathrm{NEI}_{9}$ \\
\hline 0 & 0 & 0 & 0 & 0 & 0 & 0 & 0 & 0 & 0 \\
\hline 0.5 & $5.48 \pm 1.1$ & $5.11 \pm 0.8$ & $2.26 \pm 0.3$ & $6.53 \pm 1.1$ & $3.50 \pm 0.4$ & $2.97 \pm 0.4$ & $4.99 \pm 0.3$ & $3.07 \pm 0.9$ & $2.51 \pm 0.14$ \\
\hline 1 & $7.61 \pm 1.2$ & $11.95 \pm 1.5$ & $7.35 \pm 1.1$ & $15.36 \pm 1.2$ & $6.65 \pm 1.3$ & $12.95 \pm 0.2$ & $10.78 \pm 0.3$ & $6.66 \pm 1.1$ & $6.99 \pm 0.38$ \\
\hline 2 & $9.83 \pm 0.5$ & $21.10 \pm 1.4$ & $14.3 \pm 2.2$ & $28.31 \pm 1.0$ & $11.63 \pm 1.3$ & $16.37 \pm 0.7$ & $19.14 \pm 0.5$ & $11.9 \pm 0.4$ & $11.59 \pm 0.89$ \\
\hline 4 & $15.29 \pm 0.9$ & $26.63 \pm 0.7$ & $25.54 \pm 2.1$ & $36.33 \pm 0.7$ & $17.44 \pm 0.9$ & $20.41 \pm 1.1$ & $26.52 \pm 0.7$ & $19.70 \pm 1$ & $20.02 \pm 1$ \\
\hline 6 & $23.53 \pm 0.6$ & $35.17 \pm 1.4$ & $36.26 \pm 0.09$ & $43.80 \pm 1.4$ & $25.44 \pm 0.8$ & $25.25 \pm 0.9$ & $34.87 \pm 0.9$ & $29.42 \pm 0.8$ & $25.47 \pm 0.96$ \\
\hline 8 & $34.37 \pm 1.0$ & $46.32 \pm 1.0$ & $40.75 \pm 1.1$ & $51.68 \pm 1.0$ & $33.16 \pm 0.4$ & $30.88 \pm 0.8$ & $44.30 \pm 0.3$ & $37.61 \pm 1.1$ & $31.25 \pm 1.01$ \\
\hline 10 & $46.64 \pm 1.1$ & $53.56 \pm 1.0$ & $43.43 \pm 1.2$ & $63.47 \pm 1.3$ & $43.77 \pm 0.5$ & $36.16 \pm 0.4$ & $54.30 \pm 0.9$ & $44.40 \pm 1.2$ & $37.53 \pm 1.08$ \\
\hline 12 & $64.20 \pm 1.1$ & $60.30 \pm 0.09$ & $49.43 \pm 1.4$ & $68.41 \pm 1.0$ & $51.23 \pm 0.6$ & $40.37 \pm 0.4$ & $60.84 \pm 0.6$ & $53.19 \pm 1.0$ & $44.80 \pm 1.08$ \\
\hline 14 & $88.45 \pm 0.8$ & $64.08 \pm 1.7$ & $53.53 \pm 0.9$ & $77.54 \pm 0.6$ & $60.64 \pm 1.2$ & $46.08 \pm 0.4$ & $76.31 \pm 0.5$ & $58.31 \pm 0.9$ & $48.31 \pm 0.82$ \\
\hline 16 & $99.53 \pm 0.9$ & $73.65 \pm 1.1$ & $57.65 \pm 0.6$ & $88.13 \pm 1.8$ & $67.15 \pm 0.7$ & $50.24 \pm 0.4$ & $85.12 \pm 0.6$ & $63.56 \pm 0.8$ & $50.22 \pm 0.99$ \\
\hline 18 & - & $85.40 \pm 1.0$ & $61.23 \pm 1.6$ & $99.39 \pm 1.2$ & $71.95 \pm 1.3$ & $57.72 \pm 0.9$ & $95.76 \pm 0.7$ & $68.46 \pm 0.9$ & $55.91 \pm 2.46$ \\
\hline 20 & - & $98.58 \pm 1.1$ & $66.65 \pm 1.2$ & - & $77.50 \pm 0.3$ & $62.95 \pm 1.2$ & $98.72 \pm 0.5$ & $70.37 \pm 0.8$ & $61.07 \pm 0.87$ \\
\hline 22 & - & - & $70.28 \pm 1.3$ & - & $81.31 \pm 0.9$ & $69.50 \pm 0.8$ & - & $76.28 \pm 1.0$ & $68.54 \pm 1.32$ \\
\hline 24 & - & - & $76.36 \pm 1.32$ & - & $87.40 \pm 1.17$ & $73.34 \pm 0.7$ & - & $80.71 \pm 1.1$ & $75.95 \pm 0.48$ \\
\hline
\end{tabular}

* S.D. = standard deviation.

\subsection{In Vivo Studies}

Intraocular Pressure is shown is Table 6:

Table 6. Intraocular pressure (IOP $\mathrm{mm} \mathrm{Hg}$ ).

\begin{tabular}{ccccccccccccc}
\hline \multicolumn{2}{c}{ Time (min) } & $\mathbf{0}$ & $\mathbf{3 0}$ & $\mathbf{6 0}$ & $\mathbf{9 0}$ & $\mathbf{1 2 0}$ & $\mathbf{1 5 0}$ & $\mathbf{1 8 0}$ & $\mathbf{2 1 0}$ & $\mathbf{2 4 0}$ & $\mathbf{2 7 0}$ & $\mathbf{3 0 0}$ \\
\hline \multirow{2}{*}{ Formulation } & $\mathrm{R}$ & 18.7 & 18.7 & 18.7 & 18.7 & 18.7 & 18.7 & 18.7 & 18.7 & 18.7 & 18.7 & 18.7 \\
& $\mathrm{~L}$ & 23.6 & 22.3 & 21.7 & 17.2 & 15.4 & 16.5 & 21.9 & 22.3 & 23.6 & 23.6 & 23.6 \\
\hline \multirow{2}{*}{ Marketed } & $\mathrm{R}$ & 18.0 & 18.0 & 18.0 & 18.0 & 18.0 & 18.0 & 18.0 & 18.0 & 18.0 & 18.0 & 18.0 \\
& $\mathrm{~L}$ & 21.9 & 21.7 & 4.3 & 18.3 & 19.8 & 20.8 & 21.9 & 21.9 & 21.9 & 21.98 & 21.9 \\
\hline
\end{tabular}

\subsection{Accelerated Stability Study}

Accelerated Stability studies were carried out by exposing NEI5 at various temperatures of $40{ }^{\circ} \mathrm{C}$, and $2-8{ }^{\circ} \mathrm{C}$. After a specific period of storage for stability, the in situ gel was evaluated for physi-cal parameters, in vitro drug release, and drug content.The results are showed in the Tables 7 and 8 .

Table 7. Stability studies of optimized Timolol maleate nanoemulsion in situ gel.

\begin{tabular}{ccccc}
\hline \multirow{2}{*}{ S. No } & Parameters & Initial & \multicolumn{2}{c}{ After 3 Months } \\
\cline { 4 - 5 } & & & $\mathbf{4 0}{ }^{\circ} \mathbf{C}$ & $\mathbf{2 - 8}^{\circ} \mathbf{C}$ \\
\hline 2 & $\mathrm{pH}$ & 4 & 3.9 & 4 \\
\hline 3 & Viscosity & 129 & 127 & 129 \\
\hline 4 & & & Drug Content (\%) \\
\hline 1 & Timolol maleate & 99.79 & 99.26 & 99.75 \\
\hline
\end{tabular}

Table 8. Comparative in vitro diffusion profiles of Timolol maleate nanoemulsion in situ gel before and after storage at 3 months.

\begin{tabular}{cccc}
\hline \multirow{2}{*}{ Time (h) } & \multicolumn{3}{c}{ Cumulative \% Release } \\
\cline { 2 - 4 } & \multirow{2}{*}{ Before Storage } & \multicolumn{2}{c}{ After Storage } \\
\cline { 2 - 4 } & & $\mathbf{4 0}{ }^{\circ} \mathbf{C}$ & $\mathbf{2 - 8}{ }^{\circ} \mathbf{C}$ \\
\hline 12 & 3.50 & 3.05 & 3.49 \\
1 & 6.65 & 6.12 & 6.50 \\
2 & 11.63 & 10.50 & 11.43 \\
\hline
\end{tabular}


Table 8. Cont.

\begin{tabular}{cccc}
\hline & & \multicolumn{2}{c}{ Cumulative $\%$ Release } \\
\cline { 2 - 4 } Time (h) & Before Storage & After Storage \\
\cline { 2 - 4 } & & $\mathbf{4 0}^{\circ} \mathbf{C}$ & $\mathbf{2 - 8}^{\circ} \mathbf{C}$ \\
\hline 4 & 17.44 & 15.52 & 17.29 \\
6 & 25.44 & 24.03 & 25.26 \\
8 & 33.16 & 30.13 & 32.98 \\
10 & 43.77 & 41.52 & 43.56 \\
12 & 51.23 & 49.23 & 50.98 \\
14 & 60.64 & 58.25 & 60.25 \\
16 & 67.15 & 65.50 & 66.97 \\
20 & 71.95 & 69.89 & 70.79 \\
22 & 77.50 & 75.65 & 77.42 \\
24 & 81.31 & 79.23 & 81.07 \\
& 87.40 & 83.15 & 87.35 \\
\hline
\end{tabular}

\section{Discussion}

In the present investigation, efforts were made to prepare in situ gel of Timolol maleate using surfactant and a gelling agent such as Tween 80 and Carbopol 934p, to enhance drug availability for a prolonged period and hence improve the bioavailability of ocular drugs in glaucomatous conditions. The use of the Carbopol 934p in situ gelling system is sustained by the property of its solutions to transform into stiff gels when the $\mathrm{pH}$ is raised. The two main prerequisites of an in situ gelling system are viscosity and gelling capacity.

To evaluate the rheological behavior, the viscosity of the formulation before and after the $\mathrm{pH} 4$ to 7.4 was evaluated using a Brookfield viscometer. All selected formulations were shear thinning, exhibiting pseudoplastic behavior. All formulations were liquid at room temperature and underwent rapid gelation upon raising the $\mathrm{pH} 4$ to 7.4, with Carbopol 934p formulation showing the optimum variation in viscosity. The comparative rheological properties of $\mathrm{NEI}_{5}$ formulations at different $\mathrm{pH}$ conditions indicated $129 \mathrm{cps}$ at $\mathrm{pH} 4$ and up to $265 \mathrm{cps}$ at $\mathrm{pH} 7.4$.

The results of visual appearance and clarity, $\mathrm{pH}$, gelling capacity, particle size analysis, and drug content are shown in Tables $2-4$. The results demonstrate that all prepared formulations had a clear appearance with an acceptable $\mathrm{pH}$ and drug content. Moreover, the gelling capacity of $\mathrm{NEI}_{1}, \mathrm{NEI}_{5}$, and $\mathrm{NEI}_{8}$ were found to be good, having immediate gelation, and the gel persisted for an extended period.

The particle size result showed that the average mean diameter range was $76 \mathrm{~nm}$ to $1000 \mathrm{~nm}$. The surface morphology analyzed by atomic force microscopy (AFM) result showed a uniform, spherical, and discrete particle without aggregation, which was smooth in the surface and the nanosize range, at $260.4-351.8 \mathrm{~nm}$. The FTIR spectra of formulation $\mathrm{NEI}_{5}$ showed that there were no extra peaks other than the normal peak in the spectra of the mixture of the extracts, containing active constituents, and excipients, so no evidence was found of interaction with the drug and polymers, and therefore, they are compatible with each other.

Results of in vitro release of $\mathrm{NEI}_{1}-\mathrm{NEI}_{9}$ are illustrated in Table 5 and Figure 5 , respectively. The prepared formulations such as $\mathrm{NEI}_{1}, \mathrm{NEI}_{2}, \mathrm{NEI}_{4}$, and $\mathrm{NEI}_{7}$ showed initial burst release. The regression coefficient for Timolol maleate preparation of zero-order plots was found to be $0.923,0.982$, and 0.976 from the $\mathrm{NEI}_{3}, \mathrm{NEI}_{5}$, and $\mathrm{NEI}_{8}$. The regression values for the Timolol maleate of first-order plots were found to be $0.905,0.835$, and 0.830 from the $\mathrm{NEI}_{3}, \mathrm{NEI}_{5}$, and NEI8. When the release data were subjected to Higuchi matrix plots, it was observed that formulation for Timolol maleate with regression coefficients of 0.983 , 0.990, 0.987 from the $\mathrm{NEI}_{3}, \mathrm{NEI}_{5}$, and $\mathrm{NEI}_{8}$ suggested testing diffusion-controlled release. The " $n$ " values obtained the from Korsemeyer-Peppas equation was found to be 0.836 , $0.902,0.839$ from the $\mathrm{NEI}_{3}, \mathrm{NEI}_{5}$, and $\mathrm{NEI}_{8}$. The diffusion exponent " $n$ " of the Peppas 
model was more than 0.45 , indicating the release of the drug was due to the diffusion (non-fiction) mechanism.

The higher regression coefficient values for each formulation suggested that the formulation $\mathrm{NEI}_{1}-\mathrm{NEI}_{9}$ behaved as matrix types of drug release, with formulation $\mathrm{NEI}_{5}$ having the maximum regression value. The result showed that formulation $\mathrm{NEI}_{5}$ followed zero-order drug release kinetics, which is correlated with the results of the gelling capacity study, proving that $\mathrm{NEI}_{5}$ provides immediate gelation for an extended period.

The NEI5 was sterilized by moist heat sterilization. There was no evidence of microbial growth when the formulation NEI5 was incubated for not less than 14 days at $30^{\circ}$ to $35^{\circ} \mathrm{C}$ in a fluid thioglycollate medium.

The reduction in the intraocular pressure effect of the Timolol maleate nanoemulsion in situ gel was compared with the effect of aqueous Timolet eye drops with $0.5 \% w / v$. The in situ gel formulation greatly reduced the IOP, compared with the marketed conventional formulation.

Accelerated stability testing revealed that the consistency of gel was found to be the same especially at ambient temperature, but at $40{ }^{\circ} \mathrm{C}$, there was a slight decrease inconsistency after three months. Variations were observed in $\mathrm{pH}$ values at all storage conditions; the $\mathrm{pH}$ of formulations was found to decrease slightly with time.

The maximum change was observed at $40{ }^{\circ} \mathrm{C}$. It was revealed that fewer changes in drug content and higher drug release were observed when the formulations were stored at refrigerated temperature $\left(2-8{ }^{\circ} \mathrm{C}\right)$.

\section{Conclusions}

The novel ophthalmic pH-triggered nanoemulsion in situ gel containing Timolol maleate was successfully formulated by using Carbopol 934p.

The formulation $\mathrm{NEI}_{5}$ provided reasonably constant effective levels of drug within the ocular cavity for a period of $24 \mathrm{~h}$, and the in vivo results clearly showed that the Timolol maleate nanoemulsion in situ gel $\left(\mathrm{NEI}_{5}\right)$ provided the best-sustained release of the drug in comparison with the marketed conventional dosage form. Timolol maleate nanoemulsion in situ gel formulation remained stable on storage conditions, with no apparent change in appearance, physical properties, drug content, and percentage drug release. This formulation $\left(\mathrm{NEI}_{5}\right)$ is an alternative to conventional eye drops for improving bioavailability through its longer precorneal residence time and ability to sustain drug release.

This formulation $\left(\mathrm{NEI}_{5}\right)$ also may reduce the frequency of drug administration, thus improving patient compliance. Timolol maleate nanoemulsion in situ gel $\left(\mathrm{NEI}_{5}\right)$ achieved the objective of controlled drug delivery with prolonged release and cost-effectiveness, which decreases dose and frequency of drug administration and hence can improve patient compliance. In conclusion, the stable nanoemulsion in situ gel of Timolol maleate $\left(\mathrm{NEI}_{5}\right)$ reduces the intraocular pressure over a prolonged period.

Author Contributions: K.R.V.R. contributed to writing original draft preparation. S.R. contributed to the methodology section of the research work. M.B. contributed to the conceptualization and editorial part of the research worked. R.K.P. contributed to the software and validation parts of the research work. N.H. contributed to in vitro evaluation studies and reviewed the writing of the article. M.A.A.-G. contributed to in vivo section of this research work. S.B.S., J.S. and S.T. contributed to the informal analysis of results. S.M.D. and P.D.P. contributed to the resources and evaluation section of this article. All authors have read and agreed to the published version of the manuscript.

Funding: This research received no external funding.

Institutional Review Board Statement: The in vivo study was conducted in in albino rabbits accordance with the Animal Eth-ical Committee of Periyar College of Pharmaceutical Sciences, Tiruchirappalli, Ta-milnadu, India, and approved by the Animal Ethical Committee." for studies involving albino rabbits. Approval Number (265/1/101/CPCSEA).

Informed Consent Statement: Not applicable.

Acknowledgments: The authors would like to acknowledge Sruthi Rajan for technical support. 
Conflicts of Interest: The authors declare no conflict of interest.

\section{References}

1. Soni, H.; Sharma, S. Current Update on Nanoemulsion: A Review. Sch. Int. J. Anat. Physiol. 2021, 4, 6-13.

2. Tamilvanan, S.; Kumar, B.A.; Senthilkumar, S.R.; Baskar, R.; Sekharan, T.R. Assessment of Injectable Castor Oil-Based Nano-sized Emulsion Containing Cationic Droplets Stabilized by Poloxamer-Chitosan Emulsifier Films. AAPS PharmSciTech 2010, 11, 904-909. [CrossRef] [PubMed]

3. Grigoriev, D.O.; Miller, R. Mono- and multilayer covered drops as carriers. Curr. Opin. Colloid Interface Sci. 2009, 14, 48-59. [CrossRef]

4. Shen, J.Q.; Gan, Y.; Gan, L.; Zhu, C.L.; Zhu, J.B. Ion-sensitive nanoemulsion-in situ gel system for ophthalmic delivery of flurbiprofen axetil. Acta Pharm. Sin. 2010, 45, 120.

5. Yeung, P.; Hubbard, J.; Korchinski, E.; Midha, K. Pharmacokinetics of chlorpromazine and key metabolites. Eur. J. Clin. Pharmacol. 1993, 45, 563-569. [CrossRef] [PubMed]

6. Kassem, A.; Mohsen, M.; Ahmed, S.; Essam, M. Selfnanoemulsifying drug delivery system (SNEDDS) with enhanced solubilization of nystatin for treatment of oral candidiasis: Design, optimization, in vitro and in vivo evaluation. J. Mol. Liq. 2016, 218, 219-232. [CrossRef]

7. Lee, V.H.L.; Robinson, J.R. Topical ocular drug delivery: Recent developments and future challenges. J. Ocul. Pharmacol. 1986, 2, 67. [CrossRef]

8. Cedrone, C.; Mancino, R.; Cerulli, A.; Cesareo, M.; Nucci, C. Epidemiology of primary glaucoma: Prevalence, incidence, and blinding effects. Prog. Brain Res. 2008, 173, 3-14.

9. Quigley, H.A.; Broman, A.T. The number of people with glaucoma worldwide in 2010 and 2020. Br. J. Ophthalmol. 2006, 90, 262-267. [CrossRef]

10. Friedman, D.S.; Wolfs, R.C.; O’Colmain, B.J.; Klein, B.E.; Taylor, H.R.; West, S.; Leske, M.C.; Mitchell, P.; Congdon, N.; Kempen, J. Prevalence of open-angle glaucoma among adults in the United States. Arch. Ophthalmol. 2004, 122, 532-538.

11. National Eye Institute N.I.o.H. National Eye Institute. Available online: http: / / www.nei.nih.gov / (accessed on 4 November 2011).

12. Prevent Blindness America. Prevent Blindness America. 2011. Available online: http://www.preventblindness.org/ (accessed on 4 November 2011).

13. Deshmukh, P.K.; Gattani, S.G. In vitro and in vivo consideration of novel environmentally responsive ophthalmic drug delivery system. Pharm. Dev. Technol. 2013, 18, 950-956. [CrossRef]

14. Sharma, N.; Bansal, M. Nanoemulsion: A new concept of the delivery system. Chron. Young Sci. 2010, 2, 2-6.

15. Anderson, D.R. The Optic Nerve in Glaucoma. In Duane's Ophthalmology, 15th ed.; Tasman, W., Jaeger, E.A., Eds.; Lippincott Williams \& Wilkins: Philadelphia, PA, USA, 2009; Volume 48.

16. Nair, R.V.; Shefrin, S.; Suresh, A.; Anoop, K.R.; Nair, S.C. Sustained release timolol maleate loaded ocusert based on biopolymer composite. Int. J. Biol. Macromol. 2018, 110, 308-317. [CrossRef]

17. Hegde, R.R.; Bhattacharya, S.S.; Verma, A.; Ghosh, A. Physicochemical and pharmacological investigation of water/oil microemulsion of non-selective beta-blockers for the treatment of glaucoma. Curr. Eye Res. 2014, 39, 155-163. [CrossRef]

18. Sah, A.K.; Suresh, P.K. Medical management of glaucoma: Focus on ophthalmologic drug delivery systems of timolol maleate. Artif. Cells Nanomed. Biotechnol. 2017, 45, 448-459. [CrossRef]

19. Kulkarni, G.T.; Gowthamarajan, K.; Suresh, B. Stability testing of pharmaceutical products. J. Appl. Pharm. Sci. 2004, 38, 194-198.

20. Carlfors, J.; Edman, K.; Peterson, R.; Jornving, K. Rheological evaluation of Gelrite in situ gels for ophthalmic use. Eur. J. Pharm. Sci. 2006, 6, 113. [CrossRef]

21. Cuiné, J.F.; McEvoy, C.L.; Charman, W.N.; Pouton, C.W.; Edwards, G.A.; Benameur, H.; Porter, C.J. Evaluation of the impact of surfactant digestion on the bioavailability of danazol after oral administration of lipidic self-emulsifying formulations to dogs. $J$. Pharm. Sci. 2008, 97, 995-1012. [CrossRef]

22. Lopez-Montilla, J.C.; Herrera-Morales, P.E.; Pandey, S.; Shah, D. Spontaneous emulsification: Mechanisms, physicochemical aspects, modeling, and applications. J. Dispersion. Sci. Technol. 2002, 23, 219-268. [CrossRef]

23. Biradar, S.V.; Dhumal, R.S.; Paradkar, A.R. Rheological investigation of the self-emulsification process: Effect of co-surfactant. J. Pharm. Pharm. Sci. 2009, 12, 164-174. [CrossRef]

24. Akbas, E.; Soyler, U.B.; Oztop, M.H. Physicochemical and antimicrobial properties of oleoresin capsicum nanoemulsions formulated with lecithin and sucrose monopalmitate. Appl. Biochem. Biotechnol. 2019, 188, 54-71. [CrossRef] [PubMed]

25. Abraham, S.; Furtado, S.; Bharath, S.; Basavaraj, B.V.; Deveswaran, R.; Madhavan, V. Sustained Ophthalmic Delivery of Ofloxacin From An Ion Activated Insitu Galling System. Pak. J. Pharm. Sci. 2009, 22, 175. [PubMed]

26. Jain, A.; Jain, R.; Jain, S. Basic Techniques in Biochemistry, Microbiology and Molecular Biology; Autoclave; Springer: Berlin/Heidelberg, Germany, 2020; pp. 9-10.

27. Garibaldi, B.T.; Reimers, M.; Ernst, N.; Bova, G.; Nowakowski, E.; Bukowski, J.; Ellis, B.C.; Smith, C.; Sauer, L.; Dionne, K. Validation of autoclave protocols for successful decontamination of category a medical waste generated from care of patients with serious communicable diseases. J. Clin. Microbiol. 2017, 55, 545-555. [CrossRef]

28. Viveksarathi, K.; Kannan, K. Effect of the moist-heat sterilization on fabricated nanoscale solid lipid particles containing rasagiline mesylate. Int. J. Pharm. Investig. 2015, 5, 87. 
29. Bindschedler, M.; Degen, P.; Lu, Z.L.; Jiao, X.Q.; Liu, G.Y.; Fan, F. Comparative Bioavailability of Benflumetol after Administration of Single Oral Doses of Co artemether under Fed and Fasted Conditions to Healthy Subjects. In Proceedings of the Fifth International Congress for Tropical Medicine and Malaria, Nagasaki, Japan, 17-22 November 1996; pp. 17-22.

30. Müller, R.H.; Jacobs, C.; Kayser, O. Nanosuspensions as particulate drug formulations in therapy. The rationale for the development and what we can expect for the future. Adv. Drug Deliv. Rev. 2001, 23, 3-19. [CrossRef]

31. Umapathi, P.; Ayyappan, J.; Quine, S.D. Development and validation of a dissolution test method for artemether and lumefantrine in tablets. Trop. J. Pharm. Res. 2011, 10, 643-653. [CrossRef]

32. Shanghai, B.; Aggarwal, G.; Harikumar, S. Solid self micro emulsifying drug delivery system, A review. J. Drug Deliv. Ther. 2013, $3,168-174$.

33. Gupta, E.; Barends, D.M.; Yamashita, E.; Lentz, K.A.; Harmsze, A.M.; Shah, V.P.; Dressman, J.B.; Lipper, R.A. Review of global regulations concerning biowaivers for immediate release solid oral dosage forms. Eur. J. Pharm. Sci. 2006, 29, 315-324. [CrossRef]

34. Reeshanteni, B.; Abdullah, K.; Rajermani, T. Formulation of an in-situ gelling system for ophthalmic delivery of erythromycin. Int. J. Stud. Res. Technol. Manag. 2017, 5, 1-8.

35. Campos, F.F.; Campmany, A.C.C.; Delgado, G.R.; Serrano, O.L.; Naveros, B.C. Development and Characterization of a Novel Nystatin-Loaded Nanoemulsion for the Buccal Treatment of Candidosis: Ultrastructural Effects and Release Studies. J. Pharm. Sci. 2012, 101, 3739-3752. [CrossRef]

36. Manavalan, R.; Ramasamy, C. Physical Pharmaceutics; Vignesh Publisher: Chennai, India, 1999; pp. 321, 322, $334-336$.

37. Bott, R.F.; Oliveira, W.P. Storage conditions for stability testing of pharmaceuticals in hot and humid regions. Drug Dev. Indus. Pharm. 2007, 33, 393-401. [CrossRef] [PubMed]

38. Fathordoobady, F.; Sannikova, N.; Guo, Y. Comparing microfluidics and ultrasonication as formulation methods for developing hempseed oil nanoemulsions for oral delivery applications. Sci. Rep. 2021, 11, 72. [CrossRef] [PubMed]

39. Ng, X.W.; Liu, K.L.; Veluchamy, A.B.; Lwin, N.C.; Wong, T.T.; Venkatraman, S.S. A biodegradable ocular implant for long-term suppression of intraocular pressure. Drug Deliv. Transl. Res. 2015, 5, 469-479. [CrossRef] [PubMed] 